\title{
Kajian Pola Sebaran Ruko yang Beralih Fungsi menjadi Kos-Kosan di Sekitar Kampus
}

\section{Studi Kasus : Ruko di sekitar Kampus UMN}

Vania Dea Wibowo ${ }^{1}$, Muhammar Khamdevi ${ }^{2}$

Program Studi Arsitektur, Universitas Matana ${ }^{1,2}$

\begin{abstract}
Abstrak
Tujuan penelitian ini adalah untuk mengetahui faktor-faktor yang menyebabkan ruko beralih fungsi menjadi kos-kosan terhadap potensi elemen kawasan UMN, mengetahui pola sebaran alih fungsi ruko-ruko menjadi kos-kosan di sekitar kampus dengan studi kasus ruko kos di sekitar UMN, serta mengetahui faktor-faktor penyebab pola sebaran ruko yang beralih fungsi menjadi kos-kosan tersebut dengan studi kasus ruko kos di sekitar UMN. Dewasa ini, maraknya persebaran ruko yang beralih fungsi menjadi kos-kosan terutama di sekitar pusat aktivitas. Namun, apabila persebaran ruko yang beralih fungsi sebagai kos-kosan tersebut tidak diatur sehingga akan menyebabkan pertumbuhan alih fungsi yang liar dan menyebar ke daerah-daerah lainnya yang menyebabkan kacaunya guna lahan kawasan. Penelitian ini mengambil judul "Kajian Pola Sebaran Ruko yang Beralih Fungsi menjadi Kos-kosan di sekitar Kampus, Studi Kasus: Ruko di sekitar Kampus UMN Gading Serpong." Penelitian ini dilakukan dengan menggunakan metode penelitian kualitatif deskriptif dengan bentuk penelitian studi kasus. Pengumpulan data untuk penelitian ini dilakukan dengan menggunakan observasi, wawancara, dokumentasi, diskusi kelompok terfokus dan juga triangulasi. Sumber data yang dipakai berasal dari data primer yang didapat langsung pada pengamatan di lapangan dan data sekunder yang digunakan sebagai data pelengkap atau pembanding. Penelitian ini dilakukan dengan pada bulan Maret hingga Juli 2019 pada lokasi penelitian yang telah ditentukan yakni ruko yang berada di area dengan radius $800 \mathrm{~m}$ dari UMN. Penelitian ini difokuskan dengan menggunakan teori-teori perkotaan Hamid Shirvani dan Markus Zahn sebagai alat bantu pemetaan membaca elemen kawasan untuk mendapat hasil berupa faktorfaktor penyebab alih fungsi ruko menjadi kos-kosan terhadap potensi kawasan, pola persebaran dan perubahan bangunan (terutama dalam hal ruang dan fasade) ruko-ruko yang beralih fungsi menjadi kos-kosan di sekitar kampus sebagai pusat aktivitas dengan menggunakan studi kasus ruko kos di sekitar UMN. Kesimpulan yang didapat berisi faktor-faktor alih fungsi ruko menjadi kos-kosan terhadap potensi kawasan, pola sebaran ruko kos di sekitar UMN, juga faktor pola sebaran tersebut. Kata Kunci: Pola sebaran, alih fungsi, rumah toko, kos, kampus
\end{abstract}

\section{Abstract}

The purpose of this study was to determine the factors that caused the shophouse to switch to a boarding house for the potential elements of the UMN region, to know the pattern of distribution of functions of shophouses to boarding houses around the campus with a case study of boarding houses around UMN, and to find out the factors causing the distribution pattern of shop houses that switch functions to boarding houses with a case study of boarding houses around UMN. Nowadays, the spread of shop houses that change functions into boarding houses, especially around the center of activity. However, if the distribution of shophouses that change functions as a boarding 
KAJIAN POLA SEBARAN RUKO YANG BERALIH FUNGSI MENJADI KOS-KOSAN DI SEKITAR KAMPUS

Studi Kasus : Ruko di sekitar Kampus UMN

house is not regulated so that it will cause the growth of wild function changes and spread to other areas causing disruption to regional land use. This study takes the title "Study of Distribution Patterns of Shophouse that Turns Function into Boarding Houses around Campus, Case Study: Shophouses around UMN Gading Serpong Campus." This research was conducted using descriptive qualitative research methods with case study research. Data collection for this study was carried out using observation, interviews, documentation, focus group discussions and also triangulation. Source of data used comes from primary data obtained directly from observations in the field and secondary data used as supplementary or comparative data. This research was conducted in March to July 2019 at a predetermined research location, namely a shop in an area with a radius of $800 \mathrm{~m}$ from UMN. This research is focused by using the urban theories of Hamid Shirvani and Markus Zahn as a mapping tool to read the elements of the region to get results in the form of factors that cause the change of shophouse functions into a boarding house to the potential of the area, the pattern of distribution and changes in buildings (especially in terms of space and facade) shophouses that switch functions to boarding houses around the campus as centers of activity by using case study of boarding houses around UMN. The conclusion obtained contains the factors that the function of the shop-house change into a boarding house for the potential of the area, the distribution pattern of the boarding houses around UMN, as well as the distribution pattern factors.

Keywords: Distribution pattern, function change, shop house, boarding house, campus

\section{Pendahuluan}

Dalam website Simply Homy (2018) disebutkan bahwa dewasa ini banyaknya alih fungsi ruko atau rumah toko sebagai kos-kosan. Hal ini dikarenakan permintaan akan kos-kosan sangat tinggi terutama di kawasan yang strategis atau dekat dengan kampus dan area perkantoran. Bisnis kos-kosan pun sangat menguntungkan sehingga pemilik kos-kosan mendapat penghasilan rutin untuk jangka panjang. Selain itu, pengelolaan kos-kosan juga tergolong mudah, mendapatkan relasi baru yakni para penghuni koskosan, dan dikarenakan bangunan ruko lebih terawat daripada disewakan atau dijadikan tempat usaha (website Simply Homy, 2008).

Tujuan pembangunan ruko sendiri sederhananya adalah sebagai tempat tinggal dan usaha, namun ternyata terdapat beberapa tujuan dari pembangunan ruko itu sendiri yakni antara lain untuk memenuhi kebutuhan tempat tinggal, memperoleh keuntungan bisnis, menciptakan kawasan bernuansa komersial, menciptakan kawasan multi fungsi, dan juga meningkatkan mutu pelayanan masyarakat dalam menciptakan peluang usaha (Bapedda Litbang Kota Probolinggo, 2016).

Dalam Poskota News Online (2017) disebutkan bahwa ketidaksetujuan yang terjadi diakibatkan oleh alih fungsi ruko menjadi kos-kosan pun cukup banyak di antaranya ialah pemerintah menganggap peralihan fungsi ruko sebagai kos menyalahi aturan yang berlaku dan meresahkan warga sekitar ruko dikarenakan alih fungsi ruko sebagai kos-kosan menimbulkan suara berisik yang berlebihan sehingga mengganggu waktu istirahat mereka. Tetapi tidak sedikit, yang merasa diuntungkan dengan keberadaan ruko sebagai kos-kosan yakni karena harga kos-kosan di ruko lebih murah yakni antara 900rb hingga 1 juta rupiah per bulan, tempat usaha lain di sekitar ruko yang dijadikan kos-kosan pun mendapat penghasilan dari para penghuni kos (Hafifah, 2015).

Menurut Soebroto dalam seminarnya yang berjudul "Aspek-aspek Sosial Psikologis pada Permukiman Masyarakat Berpenghasilan Rendah di Kota-kota Besar" (1983) dilihat dari segi arsitektur kota pun, 2 | Volume III Nomor 1 Agustus 2019 
keberadaan ruko ini sebenarnya dianggap merusak citra kota atau kawasan yang sudah ada. Apalagi, bila terjadi alih fungsi ruko sebagai kos-kosan yang tidak hanya mengubah fasade ruko namun juga mengakibatkan perubahan pola gerak dan sirkulasi manusia juga kendaraan di sekitarnya.

Rumah adalah tempat berlindung dan tempat berteduh manusia dalam memenuhi kebutuhan hidupnya. Sedangkan, toko adalah bangunan tempat di mana jual beli barang dan jasa berlangsung. Jadi, rumah toko ( ruko ) adalah tempat berlindung yang difungsikan sebagai tempat tinggal dan juga sebagai tempat melakukan kegiatan komersial berupa jual beli barang dan jasa (Soebroto,1983).

Menurut Hambali dalam Poskota News (2018), maraknya rumah toko menjadi area kos itu juga dikarenakan untuk ruko-ruko dengan parkir berbayar sebagian mengeluhkan omzet atau pendapatan usaha para pemilik ruko turun bahkan hingga 50 persen sehingga dengan mengalihfungsikan ruko dari tempat usaha sebagai area kos-kosan tidak membuat parkir berbayar menjadi permasalahan pemilik dikarenakan mereka tetap mendapat penghasilan rutin.

Menurut Hafifah (2015), terdapat pula keuntungan yang ditimbulkan dari alih fungsi ruko menjadi koskosan tersebut, yakni dengan adanya penghuni lain yang tinggal di ruko membuat usaha komersial yang ada di daerah tersebut berkembang misalnya dengan adanya ruko menjadi kos-kosan tersebut, ada pula tempat laundry, percetakan, rumah makan, salon, dan usaha komersil lainnya.

Selain itu, alasan lain yang menyebabkan ruko dijadikan kos-kosan menurut Anonim dalam Poskota News Online (2017) adalah dikarenakan terjadinya penolakan warga terhadap kos-kosan di area perumahan biasa. Warga merasa terganggu akibat adanya kos-kosan di lingkungan permukiman mereka sampai membuat spanduk penolakan akan keberadaan hunian rumah tinggal yang beralih fungsi menjadi kos-kosan dan warga merasa takut akan terjadinya aksi kriminalitas akibat alih fungsi hunian rumah tinggal menjadi kos-kosan tanpa izin yang resmi itu.

Pengguna kos-kosan pun rata-rata ialah pelajar, mahasiswa/i, karyawan ataupun pekerja yang tinggal di luar daerah/perantauan. Lalu untuk sebaran kos-kosan ini cenderung menggerombol di sekitar universitas atau banyak terdapat di area strategis lainnya misalnya di sekitar perkantoran, yang dikarenakan permintaan kos-kosan sangat tinggi dan tidak dapat terpenuhi. Tanpa adanya pengontrol dan penataan kawasan ruko yang menjadi area kos-kosan, maka pertumbuhannya akan semakin liar dan menyebar ke wilayah lainnya (Panji dalam Warta Kota (2018)).

Seperti contoh di area sekitar kampus UMN Gading Serpong yang mana tersebar banyak kos-kosan yang cenderung menggerombol di sekitarnya baik dalam bentuk apartemen, rumah tinggal serta ruko, namun kebanyakan kos-kosan yang ada di sekitar area ini memanfaatkan rumah toko. Kos-kosan tersebut biasa ditawarkan dengan harga yang cukup terjangkau sehingga penghuni tidak terlalu memerhatikan kelayakan, kenyamanan dan aspek lingkungan yang ada di area kos-kosan tersebut (Soedjajadi, 2005).

Berdasarkan daripada latar belakang di atas, maka dapat disimpulkan bahwa keberadaan ruko yang beralih fungsi menjadi kos-kosan di area sekitar kampus sebagai pusat aktivitas mempunyai kerugian seperti merusak citra kota, mengubah fasade ruko yang sudah ada, mengakibatkan perubahan pola gerak dan sirkulasi manusia juga kendaraan di sekitarnya. Namun, alih fungsi ruko menjadi kos-kosan juga membawa keuntungan yakni pengguna kos mendapatkan kos-kosan dengan harga yang murah dan strategis, parkir berbayar tidak memengaruhi sepi atau tidaknya ruko yang dialihfungsikan, pemilik ruko mendapat penghasilan jangka panjang. Dan terdapat pula permasalahan yang timbul sebagai akibatnya yakni apabila sebaran ruko yang beralih fungsi menjadi kos-kosan ini tidak diatur maka akan 
KAJIAN POLA SEBARAN RUKO YANG BERALIH FUNGSI MENJADI KOS-KOSAN DI SEKITAR KAMPUS

Studi Kasus : Ruko di sekitar Kampus UMN

menimbulkan pertumbuhan alih fungsi yang liar dan menyebar ke daerah-daerah lain sehingga menyebabkan kacaunya guna lahan kawasan tersebut.

Untuk itu, Penulis memilih judul Skripsi "Kajian Pola Sebaran Ruko yang Beralih Fungsi menjadi KosKosan di sekitar Kampus, Studi Kasus : Ruko di sekitar Kampus UMN."

\section{Metode Penelitian}

Pola persebaran adalah hal-hal dasar yang terbentuk sebagai akibat adanya berbagai faktor (alam, sosial, regenerasi, ko-aktif, stokastik atau gabungan) yang disebabkan oleh organisme, dan terbagi menjadi tiga yakni acak, mengelompok dan seragam. Alih fungsi berarti perubahan peruntukkan lahan. Faktor penyebab terjadinya alih fungsi lahan dan bangunan ialah dikarenakan meningkatnya kebutuhan lahan non-pertanian; peningkatan jumlah penduduk sehingga lahan yang diperlukan bertambah; meningkatkan taraf hidup masyarakat; kurang tegasnya regulasi pemerintah dalam mengatur alih fungsi lahan; serta faktor lainnya yang mempengaruhi perubahan fungsi lahan atau bangunan adalah rendahnya nilai sewa tanah atau bangunan tersebut, lemahnya fungsi kontrol dan pengawasan dari lembaga terkait, untuk mendapatkan tujuan jangka pendek atau jangka panjang berupa penghasilan tambahan pemilik tanah atau bangunan tersebut, juga dikarenakan lahan atau bangunan tersebut dianggap kurang berkembang apabila tetap dijalankan sebagaimana fungsi awalnya (Soetiknjo, 1983).

Rumah toko adalah rumah yang memiliki beberapa tingkatan lantai yang digunakan untuk beberapa fungsi campuran seperti hunian dan komersil. Rata-rata tipologi yang digunakan dalam ruko hampir mirip yakni dengan bentuk denah persegi panjang, dengan pembagian ruang berbentuk persegi dilengkapi dengan tangga dan kamar mandi, dan pembagian ruang vertikal. Kos atau kos-kosan merupakan sebuah hunian yang digunakan sebagai tempat tinggal dan menjadi kebutuhan dasar para mahasiswa yang sedang menempuh pendidikan di daerah yang jauh dari tempat tinggal asalnya. Koskosan adalah rumah tinggal yang menjadi pilihan untuk dihuni sebagian besar mahasiswa karena ditawarkan dengan harga yang terjangkau. Kos-kosan secara hukum dapat dikatakan resmi atau legal apabila izinnya diurus secara benar dan sesuai dengan peraturan yang ada dan telah ditetapkan.

Sebuah tempat yang digunakan atau dapat menampung dua atau lebih kegiatan atau aktivitas penggunanya untuk mencapai atau memenuhi sebuah kebutuhan manusia. Daerah dengan intensitas pekerjaan atau kegiatan yang lebih tinggi dibanding daerah lainnya dan memiliki kedekatan dengan zona area lalu lintas yang padat dilihat dari analisis yang telah dilakukan (Casello \& Smith, 2006). Kampus berperan sebagai pusat aktivitas sebuah kawasan. Kampus berasal dari Bahasa Latin yang berarti lapangan luas. Sedangkan, dalam pengertian yang lebih modern, kampus diartikan sebagai sekumpulan gedung-gedung universitas atau perguruan tinggi yang di dalamnya terjadi interaksi belajar mengajar antara dosen dan mahasiswa (Rutes dan Richard, 1985).

Dalam menganalisis pola sebaran yang lebih detail dapat menggunakan teori perkotaan. Teori perkotaan yang cenderung cocok dan dapat digunakan dalam penelitian ini adalah teori perkotaan Hamid Shirvani (1985) dan teori Perkembangan Kota oleh Markus Zahn (1999). Kriteria-kriteria yang terdapat pada kedua teori ini adalah sebagai berikut : kriteria teori Perkotaan Hamid Shirvani yakni : Tata guna lahan; building form and massing; sirkulasi dan perparkiran; open space; pedestrian; signages; activity support; preservasi, dan teori perkembangan kota Markus Zahn yakni: perkembangan horizontal, vertikal dan interstisial. 
Penelitian ini dilakukan dengan menggunakan metode penelitian kualitatif deskriptif dengan bentuk penelitian studi kasus. Pengumpulan data untuk penelitian ini dilakukan dengan menggunakan observasi yang dilakukan sebanyak 15 kali kunjungan, wawancara dengan pemilik ruko dan penghuni ruko, dan dokumentasi berupa foto dan video. Sumber data yang dipakai berasal dari data primer yang didapat langsung pada pengamatan di lapangan dan data sekunder yang digunakan sebagai data pelengkap atau pembanding. Penelitian ini dilakukan dengan pada bulan Maret hingga Juli 2019 pada lokasi penelitian yang telah ditentukan yakni ruko yang berada di area dengan radius $800 \mathrm{~m}$ dari UMN.

Berdasarkan pada data studi yang telah dilakukan pada tinjauan pustaka maka diperoleh hasil teori perkotaan yang dapat digunakan dalam penelitian ini adalah teori perkotaan Hamid Shirvani dan teori Perkembangan Kota oleh Markus Zahn. Kriteria-kriteria yang terdapat pada kedua teori ini adalah sebagai berikut :

Tabel 1. Hasil Data Studi Kriteria-Kriteria Penelitian ini

\begin{tabular}{|c|c|c|}
\hline No. & Kriteria & Uraian \\
\hline \multirow{9}{*}{ I. } & $\begin{array}{l}\text { Teori Perkotaan } \\
\text { Hamid Shirvani }\end{array}$ & 8 kriteria teori perkotaan Hamid Shirvani. \\
\hline & $\begin{array}{l}\text { 1. Tata Guna } \\
\text { Lahan }\end{array}$ & $\begin{array}{l}\text { Tata guna lahan yang terdapat di lokasi penelitian ialah sebagai kawasan permukiman } \\
\text { dilengkapi dengan fasilitas sarana dan prasarana pendukungnya }->\text { hubungan sirkulasi } \\
\text { dan pengguna. }\end{array}$ \\
\hline & $\begin{array}{l}\text { 2. Building Form \& } \\
\text { Massing }\end{array}$ & $\begin{array}{l}\text { 1. Bentuk dan massa bangunan membentuk suatu kawasan dan hubungan antar massa } \\
\text { 2. Kang ada. } \\
\text { 3. Bentinggian bangunan, jarak antar bangunan. } \\
\text { 4. Langgam, skala, material, tekstur, warna bangunan. } \\
\text { 5. Luas bangunan yang terbangun. } \\
\text { 6. Garis langit - horizon yang terbentuk (skyline). }\end{array}$ \\
\hline & $\begin{array}{l}\text { 3. Sirkulasi dan } \\
\text { Perparkiran }\end{array}$ & $\begin{array}{l}\text { 1. Tempat parkir memengaruhi kegiatan komersial dan pengaruh visual pada suatu } \\
\text { kawasan. } \\
\text { 2. Sirkulasi di dalam kawasan. } \\
\text { 3. Pencapaian ke kawasan mudah. } \\
\text { 4. Keberadaan sistem transportasi dari jalan publik. }\end{array}$ \\
\hline & 4. Open Space & $\begin{array}{l}\text { 1. Lansekap kawasan } \\
\text { 2. Elemen keras } \\
\text { 3. Elemen lunak } \\
\text { 4. Street Furniture } \\
\text { 5. Ruang Terbuka Hijau }\end{array}$ \\
\hline & 5. Pedestrian & $\begin{array}{l}\text { 1. Pendukung aktivitas di sepanjang jalan, adanya sarana komersial. } \\
\text { 2. Street Furniture } \\
\text { 3. Arus Pejalan Kaki }\end{array}$ \\
\hline & $\begin{array}{l}\text { 6. Signages } \\
\text { Penanda }\end{array}$ & $\begin{array}{l}\text { 1. Penanda untuk penunjuk jalan. } \\
\text { 2. Penanda untuk penunjuk tempat. } \\
\text { 3. Menghidupkan street space } \\
\text { 4. Memberi informasi bisnis. } \\
\text { 5. Menyumbang karakter fasade bangunan. }\end{array}$ \\
\hline & $\begin{array}{l}\text { 7. Activity Support } \\
\text { / Aktivitas } \\
\text { Pendukung }\end{array}$ & $\begin{array}{l}\text { 1. Aktivitas pendukung mendukung ruang publik suatu kawasan. } \\
\text { 2. Aktivitas pendukung menyediakan jalan pedestrian, plaza, menggunakan elemen } \\
\text { kota yang dapat menggerakan aktivitas. }\end{array}$ \\
\hline & 8. Preservasi & $\begin{array}{l}\text { 1. Melindungi lingkungan tempat tinggal atau permukiman } \\
\text { 2. Melindungi urban places (tempat berkumpulnya orang }->\text { pusat kawasan) }\end{array}$ \\
\hline
\end{tabular}




\begin{tabular}{|c|c|c|}
\hline \multirow{4}{*}{ II. } & $\begin{array}{l}\text { Teori Perkotaan } \\
\text { Markus Zahn }\end{array}$ & \\
\hline & $\begin{array}{l}\text { 1. Perkembangan } \\
\text { Kota Horizontal }\end{array}$ & $\begin{array}{l}\text { Perkembangan kota yang mengarah ke luar, tetapi ketinggian dan kuantitas lahan } \\
\text { terbangun tetap sama. Terdapat pada area pinggir kota dengan harga tanah yang masih } \\
\text { murah. }\end{array}$ \\
\hline & $\begin{array}{l}\text { 2. Perkembangan } \\
\text { Kota Vertikal }\end{array}$ & $\begin{array}{l}\text { Perkembangan kota yang mengarah ke atas, tetapi daerah dan kuantitas lahan terbangun } \\
\text { tetap sama, hanya saja ketinggian bangunan bertambah. Terjadi pada pusat kota di mana } \\
\text { harga lahan mahal dan terdapat potensi ekonomi. }\end{array}$ \\
\hline & $\begin{array}{l}\text { 3. Perkembangan } \\
\text { Kota Interstisial }\end{array}$ & $\begin{array}{l}\text { Perkembangan kota yang bergerak ke dalam, di mana daerah dan ketinggian bangunan } \\
\text { tetap sama yang berubah hanya kuantitas lahan dan penggunaan bangunan } \\
\text { dimaksimalkan dikarenakan area sudah dibatasi dan hanya dapat dipadatkan saja. }\end{array}$ \\
\hline
\end{tabular}

Kriteria-kriteria di atas akan digunakan sebagai alat bantu pemetaan kawasan penelitian untuk menganalisis pola penyebaran dan perubahan yang terjadi pada ruang dan fasade rumah toko yang beralih fungsi menjadi kos-kosan dan berada di sekitar kampus UMN sebagai pusat aktivitasnya.

\section{Hasil dan Pembahasan}

\section{A. Faktor-faktor penyebab ruko beralih fungsi menjadi kos-kosan terhadap potensi kawasan sekitar UMN}

\section{Tata Guna Lahan (Land Use)}

Kawasan sekitar UMN didominasi dengan area hunian yakni wilayah perumahan formal. Ada pula area komersial yang menjadi selimut hunian yakni berupa ruko-ruko berderet membentuk kompleks ruko. Sebagai pusat aktivitas kawasan ini terdapat pula area pendidikan yang berisi kampus dan sekolah.

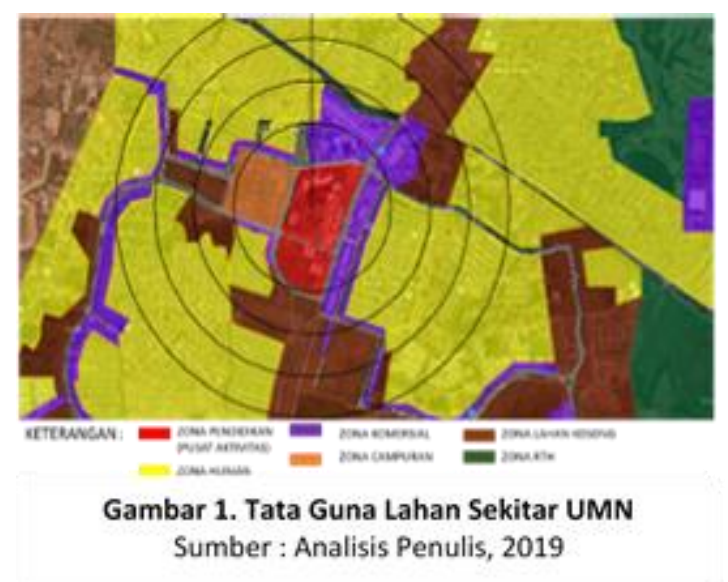

\section{Building Form \& Massing}

Kawasan ini memiliki potensi elemen fisik fasade ruko dan potensi ruang dalam ruko yang fungsional dan mudah direnovasi atau disesuaikan menjadi fungsi lain, misalnya menjadi kos-kosan. 


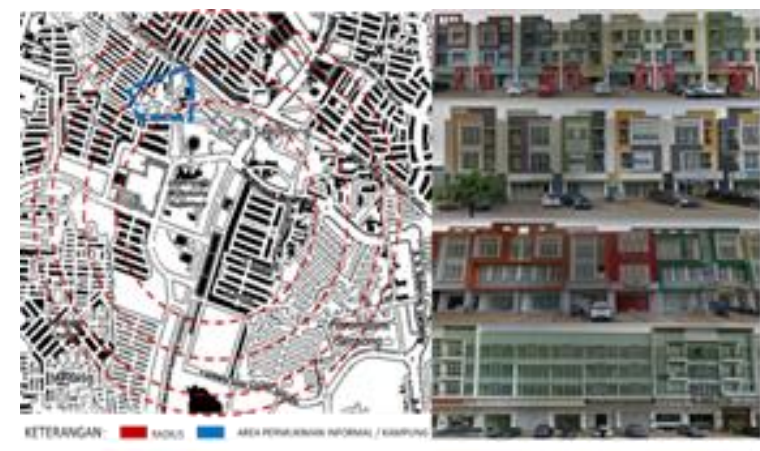

Gam bar 2. Figure \& Ground dan Fasade Sekitar UMN

Sumber : Analisis dan Dokumentasi Penulis, 2019

\section{Sirkulasi \& Perparkiran}

Kawasan ini sangat potensial dalam hal sirkulasi karena dikelilingi oleh jalan-jalan raya yang saling terhubung bahkan berada dekat dengan jalan antar kota yakni Jalan Raya Legok. Selain itu, terdapat pula potensi lahan parkir yang tersedia dan aman baik berbayar maupun tidak berbayar.

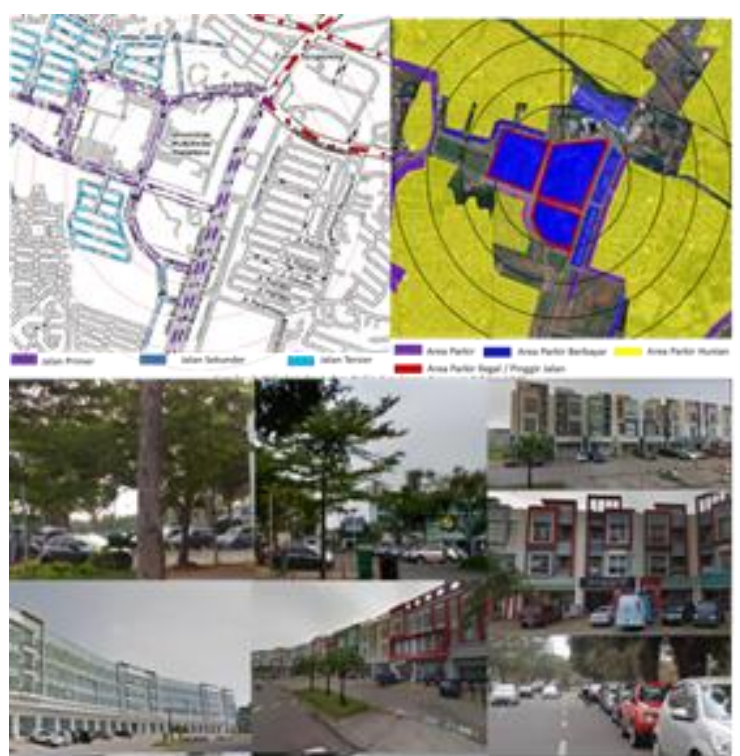

Gambar 3. Sirkulasi dan Lahan Parkir Sekitar UMN

Sumber : Analisis dan Dokumentasi Penulis. 2019

\section{Ruang Terbuka (Open Space)}

Ruang terbuka kawasan ini digolongkan menjadi ruang terbuka aktif dan pasif. Ruang terbuka kawasan ini juga terdiri dari ruang terbuka hijau dan ruang terbuka publik yang mana cocok untuk anak muda atau mahasiswa dan dapat digunakan untuk berkumpul. Ruang terbuka itu meliputi: Iahan parkir yang tersedia di depan ruko seringkali dimanfaatkan sebagai area untuk berkumpul dan berolahraga; lahan kosong yang belum terbangun juga seringkali dimanfaatkan untuk area olahraga; kawasan sekitar UMN ini setiap pagi hari di akhir pekan menutup dan mengalihkan sirkulasi kendaraan yang melintas untuk digunakan sebagai area car free day juga kawasan untuk berolahraga; tidak ada area lain yang dapat menampung komunitas selain di area kampus UMN dan juga Scientia Square Park dan Scientia Digital Center. 


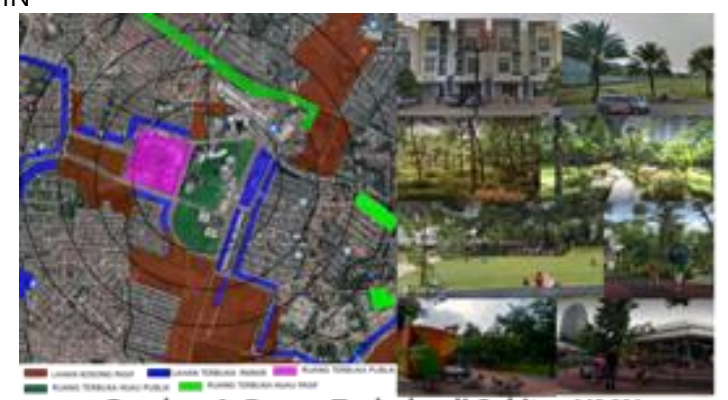

Gambar 4. Ruang Terbuka di Sekitar UMN

Sumher Analisic dan nokımentaci Penulic 2019

\section{Pedestrian}

Daerah pejalan kaki di daerah ini belum terlalu memadai karena jarak zebra cross yang jauh, juga tidak terdapat trotoar khusus untuk jalan kaki. Kawasan ini sebenarnya memiliki potensi menjadi kawasan pedestrian-friendly karena jarak cenderung dekat dan pencapaian antar fungsi mudah seperti antara ruko-ruko ke kampus.

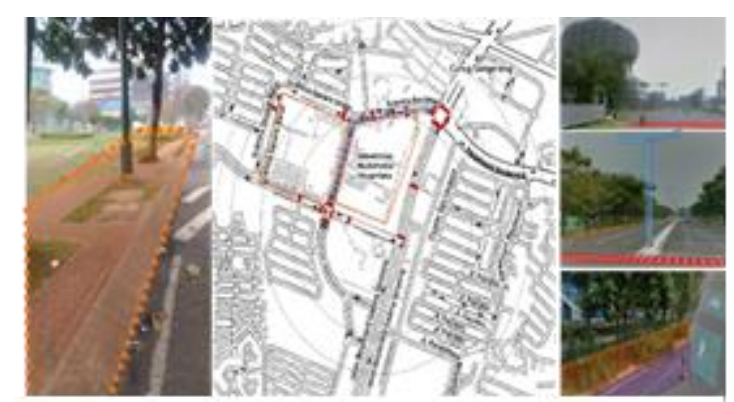

Gambar 5. Pedestrian di Sekitar UMN

Sumber : Analisis dan Dokumentasi Penulis. 2019

\section{Penanda (Signages)}

Penanda seharusnya berpotensi menjadi petunjuk kawasan. Namun untuk kawasan ini penanda fungsi-fungsi yang ada pada kawasan, penanda untuk kendaraan, sepeda maupun pejalan kaki kurang informatif. Sehingga penanda di kawasan ini belum dapat dijadikan ciri atau petunjuk kawasan sekitar UMN ini.

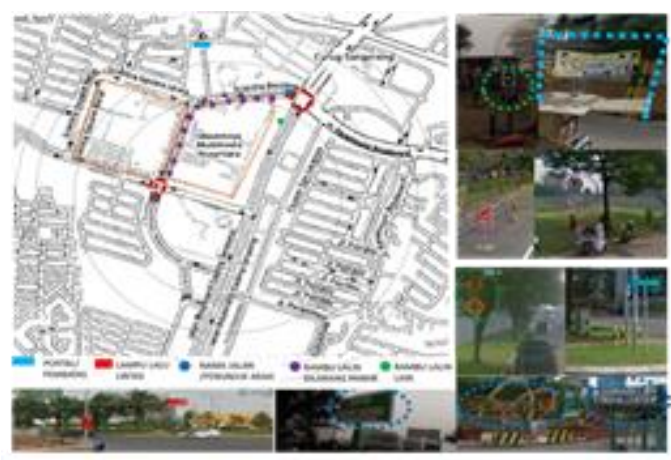

Gambar 6. Penanda di Sekitar UMN

Sumber : Analisis dan Dokumentasi Penulis. 2019 


\section{Aktivitas Pendukung (Activity Support)}

Aktivitas pendukung memunculkan fasilitas-fasilitas pendukung. Kawasan ini termasuk ke dalam kawasan yang memiliki fasilitas pendukung yang lengkap. Kampus sebagai pusat aktivitas kawasan, lalu ada pula SDC, SSQ, dan supermarket maupun minimarket sebagai fasilitas yang disediakan kawasan. Ada pula laundry, digital printing, warung makan/ restoran yang juga menjadi fasilitas tambahan terutama untuk ruko kos.

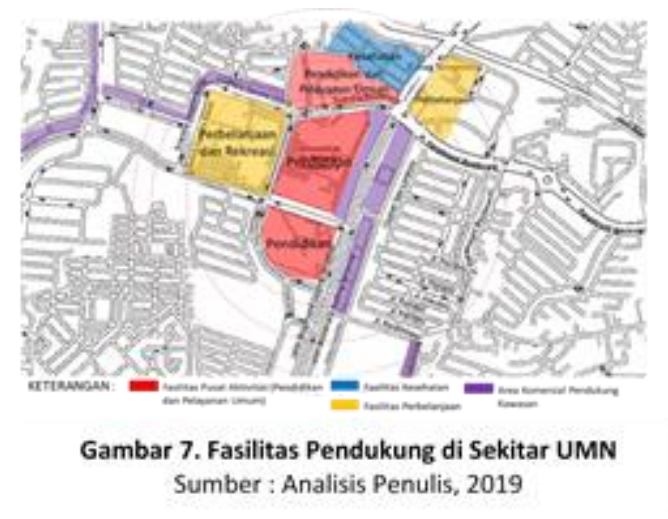

\section{Preservasi}

Keberadaan ruko pada kawasan ini sebenarnya memiliki fungsi agar daerah hunian tidak menjadi komersial. Ruko sebagai salah satu preservasi hunian. Maka dari itu, menyebabkan ruko beralihfungsi menjadi kos-kosan.

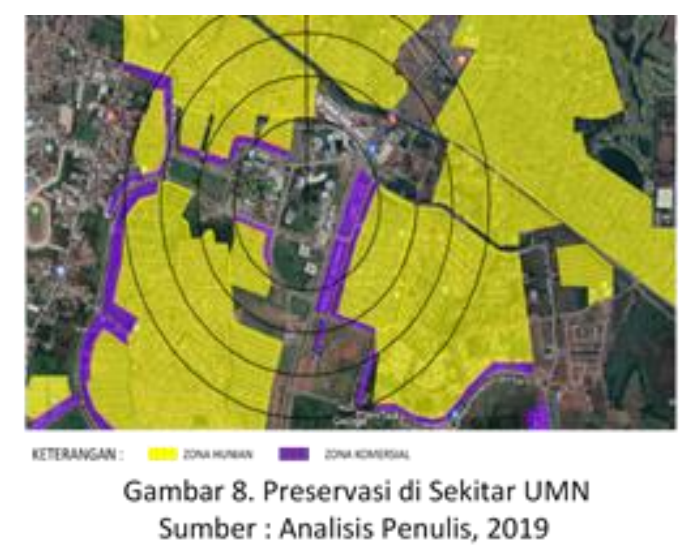

\section{Hasil Interview dengan Narasumber}

Wawancara dilakukan terhadap 2 orang narasumber yakni Bapak Anton dan Ibu A Lin atau Lina Melati sebagai pemilik ruko kos itu sendiri (terlampir). Diketahui bahwa faktor lain ruko beralih fungsi menjadi kos disebabkan karena pemilik ruko dapat memperoleh penghasilan lebih besar apabila ruko dijadikan kos-kosan dibandingkan ruko hanya disewakan atau dijadikan tempat usaha semata. Misalnya, apabila ruko dijadikan kos-kosan maka pemilik mendapat penghasilan sebesar Rp1.000.000,- - Rp2.000.000,-/bulan/kamar (satu sampai dua juta rupiah per bulan per kamar) yang mana jika ruko memiliki 15 kamar maka penghasilan yang didapat pemilik ialah sebesar Rp180.000.000,- hingga Rp360.000.000,- (seratus delapan puluh juta rupiah hingga tiga ratus enam puluh juta rupiah). Sedangkan apabila ruko disewakan maka pemilik mendapat Rp85.000.000,-/tahun (delapan puluh lima juta rupiah per tahun) saja. 
Selain itu, pemilik ruko terkadang tidak hanya memiliki satu buah ruko di satu lokasi yang sama. Beberapa pemilik juga mempunyai beberapa ruko di lokasi yang sama atau bahkan beberapa ruko di lokasi yang berbeda. Hal ini menyebabkan, ketika pemilik sudah memutuskan rukonya dijadikan koskosan di satu lokasi, maka ruko miliknya yang lain pun dapat dijadikan kos-kosan juga walau berada di lokasi yang berbeda. Karena pemilik hanya ingin memiliki satu jenis usaha yang sama yakni bisnis kos-kosan di ruko supaya lebih mudah dikelola.

\section{B. Pola Sebaran Ruko Kos di Sekitar UMN terhadap Potensi Kawasan}

Sebelum membahas pola sebaran ruko kos, akan lebih baik membahas dahulu pola sebaran koskosan di sekitar UMN secara makro. Berikut ini adalah pemetaan yang telah dilakukan.

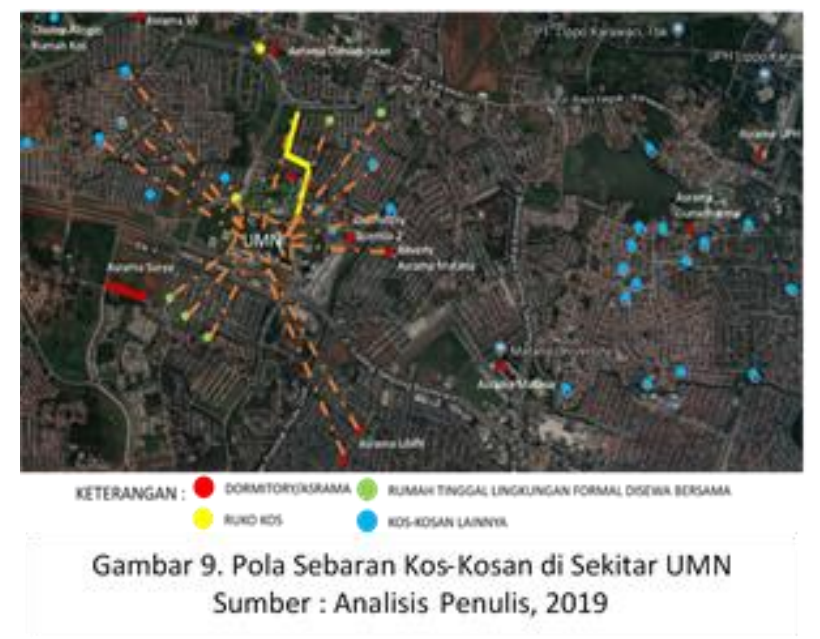

Pola sebaran kos-kosan di daerah ini cenderung menyebar dari daerah yang dianggap sebagai pusat kawasan yakni kampus UMN. Sebaran kos-kosan ini ke depannya akan banyak terjadi pada kawasan yang memiliki radius terdekat dengan UMN atau dapat dikatakan semakin dekat dengan kampus maka lahan semakin besar peluangnya apabila dijadikan kos-kosan.

Apabila hasil observasi dan pemetaan yang telah dilakukan ini dihubungkan dengan teori perkembangan kota Markus Zahn maka dapat dilihat pengembangan kawasan sekitar UMN ini tergolong ke dalam perkembangan kawasan horizontal di mana perkembangan kawasan mengarah ke luar dengan ketinggian bangunan dan kuantitas lahan terbangun yang tetap sama. Hal ini dikarenakan kawasan ini masih tergolong ke dalam wilayah pinggir kota dengan harga tanah yang cenderung tidak terlalu mahal.

Lalu, pembahasan dikerucutkan ke dalam kawasan ruko kos yang berada di sekitar UMN saja. Di mana pola sebaran ruko yang beralih fungsi menjadi kos-kosan di sekitar UMN terkait potensi elemen kawasan ialah cenderung lebih kuat ke arah Barat karena terdapat jalan-jalan besar antar kota seperti Jalan Raya Legok yang menghubungkan Kota Bogor hingga Kota Tangerang. Hal ini yang menyebabkan ruko kos memiliki akses yang mudah dijangkau dan penghuni ruko kos dapat dengan mudah pulang ke daerah asalnya menggunakan transportasi antar kota yang tersedia. 


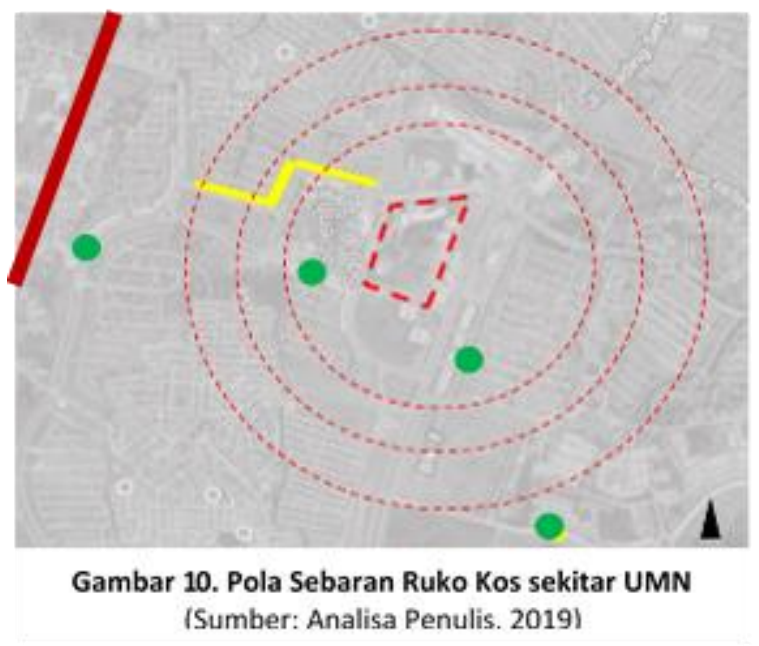

Tetapi ada potensi pola sebaran menyebar ke arah Selatan UMN. Hal ini disebabkan karena adanya akses jalan raya yang menghubungkan kawasan Gading Serpong dengan kawasan BSD, juga karena cukup dekat dengan stasiun-stasiun seperti stasiun Cisauk, stasiun Serpong dan stasiun Rawa Buntu.

\section{Kesimpulan}

Berdasarkan dari pemetaan dan observasi lapangan, juga wawancara yang telah dilakukan maka dapat disimpulkan sebagai berikut :

1. Faktor-faktor penyebab ruko beralih fungsi menjadi kos-kosan terhadap potensi kawasan sekitar UMN yaitu sebagai berikut:

a. Dari hasil analisis, faktor-faktor yang berperan adalah :

1) Keberadaan kampus sebagai pusat aktivitas dan ruko sebagai area komersial mendorong alih fungsi ruko menjadi kos-kosan;

2) Elemen fisik fasade dan ruang dalam ruko cenderung lebih fleksibel disesuaikan atau direnovasi menjadi kos-kosan;

3) Sirkulasi dan parkir kendaraan tersedia dan aman;

4) Ruang terbuka cukup memadai untuk memfasilitasi aktivitas mahasiswa di luar kampus;

5) Jarak ruko dan kampus dekat sehingga dapat ditempuh dengan berjalan kaki;

6) Memiliki fasilitas yang lengkap berupa kampus sebagai pusat aktivitas didukung dengan SDC, SSQ, supermarket, minimarket, laundry, digital printing, warung makan/restoran, dan sebagainya;

7) Karena adanya potensi untuk melakukan preservasi maka ruko jadi kos-kosan untuk melindungi hunian dari komersial.

b. Dari hasil wawancara, maka faktor-faktor yang berperan adalah :

1) Pemilik berpotensi mendapat penghasilan lebih besar dari penggunaan ruko menjadi kos-kosan dibandingkan ruko hanya disewakan atau dijadikan tempat usaha semata;

2) Faktor kepemilikan ruko oleh satu orang yang sama dan pemilik hanya menginginkan satu jenis usaha agar mudah dikelola juga pemilik menganggap bisnis ruko kos lebih menguntungkan.

2. Pola sebaran ruko yang beralih fungsi menjadi kos-kosan di sekitar UMN terkait potensi elemen kawasan ialah cenderung lebih kuat ke arah Barat karena terdapat jalan-jalan besar antar kota seperti Jalan Raya Legok yang menghubungkan Kota Bogor hingga Kota Tangerang. Hal ini yang menyebabkan ruko kos memiliki akses yang mudah dijangkau dan penghuni ruko kos dapat dengan mudah pulang ke daerah asalnya menggunakan transportasi antar kota yang tersedia. 
KAJIAN POLA SEBARAN RUKO YANG BERALIH FUNGSI MENJADI KOS-KOSAN DI SEKITAR KAMPUS

Studi Kasus : Ruko di sekitar Kampus UMN

Tetapi ada potensi pola sebaran menyebar ke arah Selatan UMN. Hal ini disebabkan karena adanya akses jalan raya yang menghubungkan kawasan Gading Serpong dengan kawasan BSD, juga karena cukup dekat dengan stasiun-stasiun seperti stasiun Cisauk, stasiun Serpong dan stasiun Rawa Buntu.

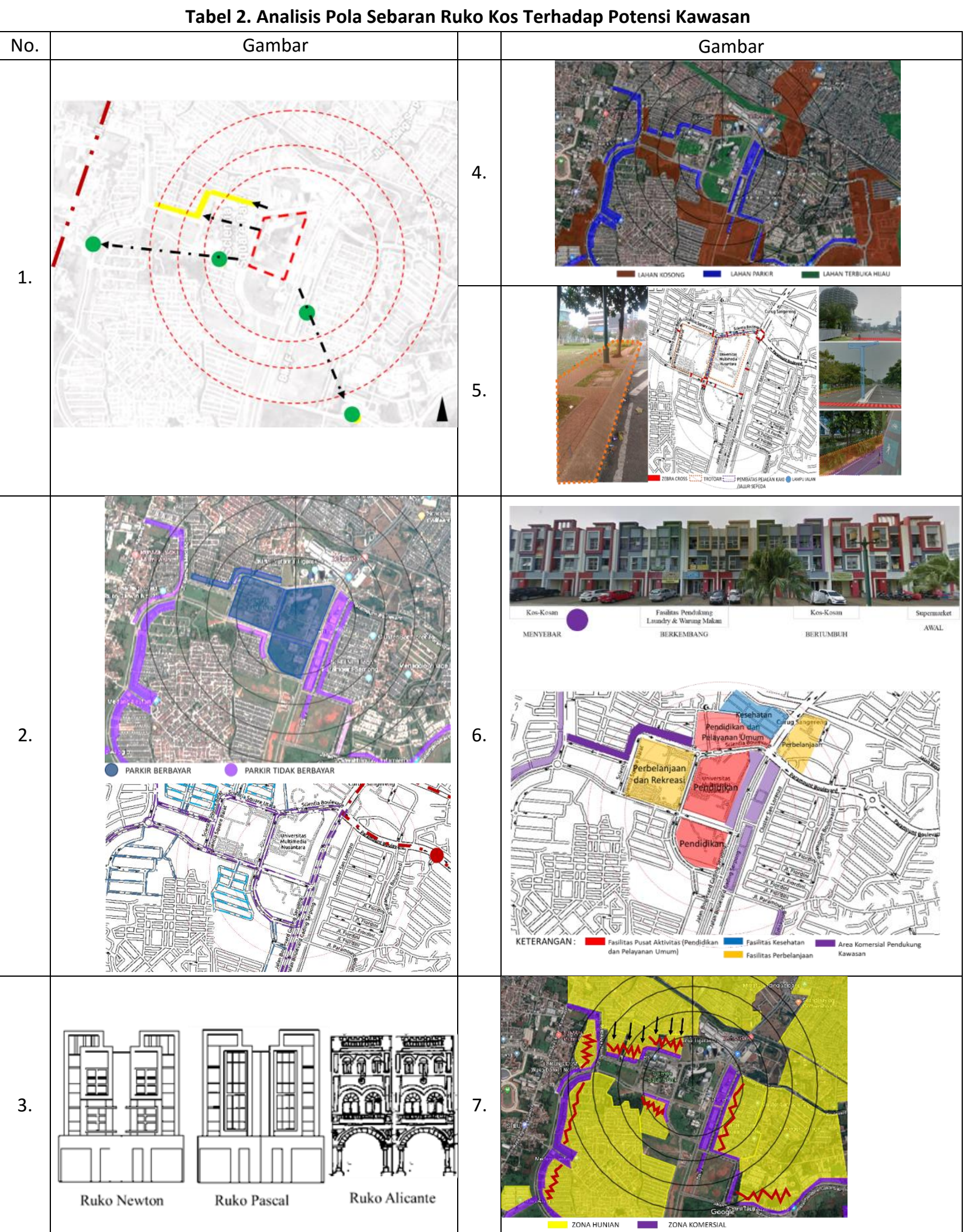


3. Faktor-faktor pola sebaran ruko kos di sekitar UMN mencakup banyak faktor yang juga terkait dengan potensi elemen kawasan UMN bisa dilihat dari tabel 2. Maka dapat disimpulkan bahwa faktor-faktor tersebut ialah sebagai berikut:
a. Pola sebaran ruko kos mengikuti pola kompleks atau deretan ruko;
b. Tersedianya akses, sirkulasi, dan fasilitas parkir kendaraan yang aman dan memadai.
c. Bangunan ruko 3 lantai; memiliki jendela-jendela berukuran kecil; memiliki arcade, teras, dan balkon; lantai dasar cenderung menjorok ke dalam dibanding lantai di atasnya; lantai dasar cenderung tertutup.
d. Tersedianya ruang terbuka untuk dimanfaatkan mahasiswa.
e. Tersedianya zebra cross dari ruko ke kampus.
f. Kampus sebagai pusat konsentrasi aktivitas.
g. Tersedianya fasilitas pendukung berupa supermarket, SDC, SSQ, laundry, digital printing, tempat makan/restoran.
h. Larangan hunian dan kawasan perumahan untuk dijadikan area komersial atau kos-kosan.

\section{Saran}

Terkait dengan potensi kawasan yang sudah ada, akan lebih baik apabila memperbaiki kekurangankekurangan fasilitas yang belum memadai di kawasan sekitar UMN tersebut di antaranya :

1) Mengembangkan kawasan sekitar UMN menjadi kawasan pedestrian-friendly yakni dengan menyediakan zebra cross pada jarak-jarak tertentu atau sarana penyeberangan, trotoar yang ideal untuk para pejalan kaki, vegetasi-vegetasi dan street furniture ditambah sehingga pejalan kaki merasa aman dan nyaman melalui kawasan tersebut.

2) Terkait dengan lahan parkir untuk mengurangi parkir illegal atau parkir di pinggir jalan akan lebih baik diberikan akses kartu parkir per tahun sebagai fasilitas kampus ataupun penghuni ruko, dengan harga yang lebih terjangkau bahkan harga khusus untuk mahasiswa.

3) Kawasan ini memerlukan tambahan penanda yang lebih informatif dan dapat dijadikan ciri khas kawasan.

4) Fasilitas pendukung yang ada di kawasan ini sudah memadai, namun akan lebih baik ditambahkan jalur khusus bagi sepeda atau cycle track, halte transportasi online maupun transportasi ramah lingkungan seperti bis kendaraan tenaga surya atau solar bus, bis listrik atau electric bus untuk digunakan para mahasiswa.

5) Ruko yang beralih fungsi menjadi kos-kosan memerlukan beberapa penyesuaian dan penambahan ventilasi agar sirkulasi udara dan cahaya matahari masuk ke dalam setiap kamar kos.

Agar pola sebaran ruko kos tidak menyebar ke daerah lain dan tidak menimbulkan munculnya ruko kos illegal maka terdapat beberapa saran dari Penulis sebagai solusi dari permasalahan tersebut yakni :

1) Developer menyediakan ruko kos sebagai kelanjutan atau penambahan dari ruko kos yang sudah ada dan ruko kos ini disewakan dengan harga terjangkau;

2) Karena salah satu yang dicari para mahasiswa adalah tempat tinggal yang murah maka dapat juga dibangun asrama mahasiswa dengan tempat tidur bertingkat yang berada dekat dengan kawasan UMN;

3) Kos sendiri hanya berfungsi sebagai tempat tinggal yang mana seringkali digunakan hanya untuk tidur ketika pulang kuliah maupun beraktivitas maka dapat juga diterapkan konsep kos-kosan atau ruko kos legal yang berbentuk hotel kapsul atau dimanfaatkan hanya untuk kamar-kamar ukuran kecil yang dilengkapi oleh fasilitas pendukung sehingga dapat menampung lebih banyak mahasiswa dan harga yang ditawarkan dapat lebih murah. 
KAJIAN POLA SEBARAN RUKO YANG BERALIH FUNGSI MENJADI KOS-KOSAN DI SEKITAR KAMPUS Studi Kasus : Ruko di sekitar Kampus UMN

\section{Daftar Pustaka}

A. Rutes, Walter and Richard Penner. 1985. Hotel Planning and Design. New York.

Achmad, Fauzan. (2013). Pusat Kegiatan dan Dokumentasi Arsitektur. Malang : Skripsi UIN Malang

Amiruddin, Afriani. (2014). Pengaruh Keberadaan Universitas Haluoleo terhadap Perubahan Tata Guna Lahan di Kawasan Andonuohu Kota Kendari. Semarang : Skripsi Universitas Diponegoro.

Anton. (2017). "Ruko jadi Kos-kosan Warga Kelurahan Depok Resah". Poskota News. [accessed: 2 Maret 2019,12.00WIB].http://poskotanews.com/2017/11/18/ruko-jadi-kos-kosan-membuat-wargakelurahan-depok-resah/

Bungin, Burhan (2008). Metodologi Penelitian Kualitatif. Jakarta : Raja Grafindo Persada.

Choirurrozi, Moch. (2008). Pola Persebaran Permukiman di Kecamatan Prambanan Kabupaten Klaten tahun 2008. Surakarta : Skripsi thesis Universitas Muhammadiyah Surakarta.

Creswell, J.W. (2007). Qualitative Inquiry and Research Design : Choosing among Five Approaches ( $3^{\text {rd }}$ ed.) Thousand Oaks. CA : Sage.

Direktorat Tenaga Kependidikan. (2008). Pengolahan dan Analisis Data Penelitian. Direktorat Jenderal Peningkatan Mutu Pendidik dan Tenaga Kependidikan Departemen Pendidikan Nasional.

Echols, John M. dan Hassan Shadily. 2005. Kamus Inggris Indonesia : An English - Indonesian Dictionary. Jakarta: PT Gramedia

Hutchinson, G. E. (1953). The Concept Of Pattern Ecology. Proceedings Academy Natural Sciences,Philadelphia, dalam Ludwig \& Reynolds. (1988). Statistical Ecology. John Wiley and Sons. New York.

Keputusan Gubernur DKI Jakarta Nomor 2693 Tahun 1987 Tentang Pedoman Pengaturan Perumahan Pemondokan dalam Wilayah DKI Jakarta.

Kostof, Spiro. (1991). The City Shaped. London

Lynch, Kevin. (1960). The Image of the City. Cambridge, Mass: MIT

Marshall, C. Rossman, G (1999). Designing Qualitative Researce. Yd Ed. Sage Pub.

Newman, P..., Kenworthy, J. (1999) Sustainability and Cities: Overcoming Automobiles Dependence, Washington DC: Island Press

N.n. (2018). "Inilah 9 Alasan Bisnis Kos Kosan menjadi Bisnis yang Menguntungkan". Simply Homy. [accessed: 2 Maret 2019, 12.10WIB]. http://www.simplyhomy.com/2018/08/bisnis-kos-kosan/

N.n. (2018). "Pertumbuhan Ruko (Rumah Toko) di Kota Probolinggo". BAPPEDA LITBANG. [accessed: 2 Maret 2019, 12.20WIB]. http://bappedalitbang.probolinggokota.go.id/index.php/artikelperencanaan/137-pertumbuhan-ruko-rumah-toko-di-kota-probolinggo

N.n. (2018). "Omzet Turun 50\%, Ratusan Pemilik Usaha Demo Tolak Keberadaan Parkir Berbayar". Okezone News. $\quad$ [accessed: 2 Maret 2019,12.30WIB].https://news.okezone.com/read/2018/11/20/338/1980095/omzet-turun-50ratusan-pemilik-usaha-demo-tolak-keberadaan-parkir-berbayar/

N.n. (2018). "Pengertian dan Definisi Pusat". KBBI Online. [accessed: 2 Maret 2019,12.40WIB].https://kbbi.web.id/pusat/

Odum, E. P. (1971). Dasar-Dasar Ekologi. Yogyakarta : Edisi ketiga Gadjah Mada University Press.

Peraturan Daerah Kota Makassar Nomor 10 Tahun 2011 Tentang Pengelolaan Rumah Kos.

Peraturan Daerah Kota Palangkaraya Nomor 16 tahun 2011 tentang Izin Usaha Pengelolaan Rumah Kos dan Barak.

Peraturan Daerah Kota Pekalongan Nomor 15 tahun 2015 tentang Penyelenggaraan Rumah Kos.

Pratama, Rizky T. (2013). Pengawasan Dinas Tata Ruang dan Bangunan terhadap Alih Fungsi Bangunan Rumah Toko di Kota Pekan Baru tahun 2013. Riau : Jurnal UNRI.

Primyas, Mitsnein Luthfie Endry (2016). Alih Fungsi Tanah dari Rencana Perumahan menjadi Rumah Sakit Perspektif Maslahah Mursalah. Malang : Skripsi Universitas Islam Negeri Maulana Malik Ibrahim.

Rajaguguk, Erman (1995). Hukum Agraria, Pola Penguasaan Tanah dan Kebutuhan Hidup. Jakarta : Candra Pratama.

Rosadi, Dadi dan Feby Oktarista Andriawan. (2016). Aplikasi Sistem Informasi Pencarian Tempat Kos di Kota Bandung Berbasis Android. Jurnal Computech \& Bisnis STMIK MI Vol. 10 No. 1, Juni 2016, 5058 ISSN 2442-4943. 
Rosalia, Tara. (2005). Aktivitas Belajar. [accessed: 2 Maret 2019,12.50WIB]. http://id.shvoong.com/socialsciences /1961162-aktifitas-belajar/

Setiawan, Andreas. (2008). Gambaran Konsep Diri pada Mahasiswa. Depok: Fakultas Psikologi Universitas Indonesia.

Shirvani, Hamid. (1985). The Urban Design Process. Van Nostrand Reinhold: New York

Sihombing, Irine Eka. (2009). Segi-segi Hukum Tanah Nasional dalam Pengadaan Tanah untuk Pembangunan. Jakarta : Universitas Tri Sakti cetakan kedua.

Soebroto, Endah Parwita. (1983). Aspek-aspek Sosial Psikologis pada Permukiman Masyarakat Berpenghasilan Rendah di Kota-kota Besar. Bandung.

Soeitoe, Samuel. (1982). Psikologi Pendidikan. Jakarta: Lembaga Penerbit Fakultas Ekonomi Universitas Indonesia

Soetiknjo, Iman (1983). Politik Agraria Nasional. Yogyakarta : Gadjah Mada University Press.

Sugiyono. (2013). Metode Penelitian Pendidikan (Pendekatan Kuantitatif, Kualitatif, dan R\&D). Bandung : Alfabeta.

Tohir, Rizki Kurnia. (2016). Pola Sebaran Kayu Afrika (Maesopsis eminii, Engl.) di Arboretum Fakultas Kehutanan IPB. Bogor :Repository IPB.

Trancik, Roger. (1986). Finding Lost Spaces: Theories of Urban Design. John Wiley and Sons: USA

UU Nomor 2 Tahun 1981 Tentang Metrologi Legal Pasal 1 Huruf $p$.

Wahyudi, Agung (2005) Pengaruh Perubahan Bentuk Ruko Terhadap Morfologi Kawasan Margonda Raya Depok. Proceeding, Seminar Nasional PESAT 2005.

Wicaksono, Andie A. (2007). Ragam Desain Ruko (Rumah Toko). Jakarta : Penebar Swadaya.

Yusuf, A. Muri. (2014). Metode Penelitian Kuantitatif, Kualitatif \& Penelitian Gabungan. Jakarta : Kencana. Zahnd, Markus. (1999). Perancangan Kota Secara Terpadu. Penerbit Kanisius: Yogyakarta. 